\title{
Comparative Analysis of the Refusal Language between 2 Broke Girls and Ode to Joy
}

\section{Yi Lingling ${ }^{1}$, Tian Chuanmao ${ }^{2}$}

School of Foreign studies, Yangtze University, Hubei, 434023 PRC China.

Received: 11 Oct 2020; Received in revised form: 13 Nov 2020; Accepted: 15 Nov 2020; Available online: 19 Nov 2020

(C)2020 The Author(s). Published by Infogain Publication. This is an open access article under the CC BY license

(https://creativecommons.org/licenses/by/4.0/).

\begin{abstract}
Rejection, as an indispensable part of interpersonal communication, is a negative response to suggestions, invitations, offers and requests. Because of the differences in language and cultural background, in the same situation, there are many similarities and differences in strategy between China and the United States. If we do not pay attention to these differences, the rejected will be confused or even enraged. As a result, the relationship between the rejected and the rejected is not well maintained, as a result of which the relationship between the rejected and the rejected is not well maintained.

The purpose of this study is to explain the similarities and differences of rejection strategies between China and America by comparing the two TV serials 2 Broke Girls and Ode to Joy. This paper not only studies the rejection strategies in English or Chinese, but also analyzes and expounds them from the perspective of Chinese and American comparison. Combining theoretical analysis with empirical analysis, the study of rejection language is more comprehensive and specific.
\end{abstract}

Keywords - Direct rejection, Rejection strategy, Politeness principle.

\section{INTRODUCTION}

Rejection, as an indispensable part of interpersonal communication, is a negative response to suggestions, invitations, offers and requests, a speech act that threatens face. Since it is essentially a threat to the face of both communicators, it requires the careful treatment of the speaker and the correct interpretation of the listener, which puts forward a higher demand for the communicative pragmatic competence.

In order to ensure the smooth communication, people will adopt certain strategies, which vary from person to person, and the rejection strategies of people in different cultural backgrounds will also be different. Only by knowing yourself and knowing each other can we be able to avoid all kinds of pragmatic failures and ensure the smooth progress of communication. Pragmatic principles and strategies are more acceptable of social and cultural networks than social and cultural networks, rather than in ISSN: 2456-7620 order to succeed in communication and interference with human beings. Indirect rejection is a special pragmatic strategy, driven by intention and purpose. The research is more about enumerating and describing the corpus, lack of a systematic classification of rejection. In the analysis of the factors that affect the choice of refusal strategy, it is limited to the social status, social power and cultural factors, while neglecting the role of both sides of the communication.

In theory, this study not only enriches the theory of refusal speech act, but also widens the scope of application of these theories. In practice, the study provides a lot of rejection techniques to help us minimize the threat to face while achieving the goal of rejection, helping to preserve our own interests and social relationships. In addition, the study will deepen the understanding of western culture and provide some inspiration for cross-cultural communication and English teaching.

The purpose of this study is to explain the similarities 
and differences of rejection strategies between China and America by comparing the two TV serials 2 Broke Girls and Ode to Joy. The content of the study is divided into roughly three parts. In the first part, it will introduce the similarities of rejection strategies in 2 Broke Girls and Ode to Joy, then the differences of rejection strategies and finally find out the the causes of differences.

\section{THE SIMILARITIES OF REJECTION STRATEGIES IN2 BROKE GIRLS AND ODE TO JOY}

\subsection{The Use of Rejection Strategies in Indirect Way}

Indirect refusal belongs to an interrogative speech act, which refers to the indirect completion of another-an extra-verbal act-by means of an extra-verbal act. Searle has proposed In indirectspeech acts the speaker communicates to the hearer more thanhe actually says by way of relying on their mutually sharedbackground information, both linguistic and non-linguistic.Together with the general powers of rationality and inference onthe part of the hearer. In indirect speech act, if communication does not directly say what it wants to say in indirect speech act, it expresses its intention indirectly by another (often direct) speech act. And the speaker uses the knowledge shared with the listener to convey his implication to the listener. It emphasizes the tone of the string and the meaning of the words.

In daily life, there are three types of dialogue with the most obvious form of question-and-answer, namely, request, invitation or proposal. The difference between indirect refusal and direct rejection lies not only in whether there is "No", but also in whether to propose other relative buried causes. In the analogy strategy of indirect refusal, the use of objects and figurines plays a very good role in refusing. The image of Max in 2 Broke Girls has always been a mean tongue, but the answer is often in a serious manner.

The highest rate of indirect rejection was found that the frequency of indirect rejection was also observed in this TV series. The protagonists in 2Broke Girls are familiar with each other and depend on each other. Because of familiarity, direct rejection would be too hurt, and it also can not show the fun of the protagonist. Therefore, indirect refusal is most appropriate.

In different situations people choose different ways to reject. In formal request or invitations people prefers to ISSN: 2456-7620 choose the indirect ways to reject to keep the relationship of each other.

\subsubsection{Refuse to Formal Request}

When it comes to the formal request situation, people in both two countries would like to reject someone in a indirect way. We can see from two TV serials 2 Broke Girls and Ode to Joy. There are some examples.

Example 1: (Ode to Joy, Season 1Episode 6)

Qi Dian: "I just found a few friends eating here. Would you mind having a table with them? They take the mouth with their families."

Andy: “I'm not so comfortable with my family. I'm sorry."

Qi Dian: “OK, then ignore them.”

This was the second time Andy met Qi Dian in a public place, so when he invited Andy to sit with his friends. Instead of saying "No, I don't want to." She chose to say "I'm not so comfortable with my family." That decline the invitation in a in direct way. Then "I'm sorry." to apologize this behavior. Most Chinese may like Andy to reject this invitation indirectly. Because saying it directly may lose one's face. There is also common in America.

Example 2: (2 Broke Girls, Season 4Episode 11) Sophie:"Max, do you want be my maid of honor?" Max:"I would be eaten alive by a rabbit, which would take a long time and be a less embarrassing."

In season 4, Polish-born neighbor Sophie decided to marry the restaurant's chef, Oleg. When asked if Max would like to be her bridesmaid, Max's answer was clearly no, and compared the feeling of being a bridesmaid rather than being embarrassed by the fact that she would rather be a raw rabbit.

Taking these examples is to show that in these two TV series, they are often reject people in a indirect way when they are in a formal situation. Both Chinese and America know the importance of saving one's face in front of the public place. This is called "Politeness principle."

\subsubsection{Refuse to Invitation}

Fuzzy strategy means giving the speaker vague questions and answering them in the form of listening or mislistening questions.

Example 1: (2 Broke Girls, Season 4 Episode 18) Caroline:"Sophie. I've been looking at color choices, and how would you feel about us in a nude?" 
Sophie:"Max could go nude but you don't have the rackto pull it off."

As Sophie approached her wedding date, when Caroline asked her bridesmaid to wear a naked (nude) dress, Sophie deliberately sounded "nude" as "naked" and satirized Caroline's poor figure, which no one would be interested in. Here Sophie makes use of nude's pun, not only to reject the suggestion of wearing naked color indirectly, but also to satirize the taste of Caroline.

\section{Example 2: (Ode to Joy, Season 1Episode 11)}

Lin: "Hello, Guan, Are you ready to pack up your things when you go home?"

Guan Juer: "Excuse me, bro. Our company is temporarily going to change a very large project, and then our boss tells us that everyone has to stay and work overtime. I may not be able to go back with you."

Lin: “That's a shame. It's okay. There's nothing I can do about it."

Guan Juer has packed her luggage, but still use“"need to do extra work"as an excuse to refuse my Lin's invitation to go back home together.

In these two examples showing that once there is an invitation,it is hard to say no or refuse it directly in both two countries. In 2 Broke Girls, Sophie uses a humour way to reject the Caroline's suggestion of wearing a nude bridesmaid dress. It is not only saying no to her but also in a joke way. It is the same in Ode to Joy. Guan is afraid to hurt Lin's feeling when saying no directly. So she made up some reason like working overtime to refuse going home with him. Therefore the reaction in these two TV series exactly reflects an indirect ways in rejection.

\subsubsection{Social Statue or Higher-ups}

Sometimes, because of the power relationship, refusal becomes more difficult. For example, when the person who gives up the task is his or her own officer or senior colleague, you also have to worry that if you refuse the task, it will be regarded as insufficient effort, not willing to dedicate, "disobeying your boss."

Because executives or colleagues are willing to hand things over to you, it may be to value and appreciate your abilities. But on the premise of knowing how to assess one's ability, if you feel that time, ability is limited, or your supervisor's request is not reasonable, you still have to tactfully reject it. It is best to communicate with your boss or someone who ISSN: 2456-7620 has more power than yourself. When you feel unable to take over the task, you have to use specific evidence to illustrate your difficulties. For example, when you have several projects that must be completed before the date, which plans cannot be postponed, periods need to be available for meetings, rather than simply responding to "no." There are specific facts, support is called reason, nothing is easy to be used as an excuse and even if promised, you should also let the other party see your sacrifice specially in cross-departmental cooperation.

Example: (2 Broke Girls, Season 2 Episode 18)

Secretary: "Most people leave after two hours."

Caroline: "Well, it's not a problem for us. We'll wait two hours, three, a whole day.

Secretary: "That sounds about right."

Aunt: "Stephanie."

Secretary: “Coming. That's not my name, but I'm afraid to tell her." (speak to Caroline.)

The secretary's name is not Stephanie, but being afraid of boss. So, she didn't to correct it.

Example 2: (Ode to Joy, Season 1 Episode 16)

Guan: "Manager, what's wrong?"

Manager: "How did you check it out, didn't you find such a big mistake? There was an error in the original data, and the rest of the scheme was done in vain."

Guan: "This case was originally Michelle's. She said she was sick, and I took it."

Manager: "I don't care so many of you, since you take over should do well, I only ask you, who is the last signatory, is not you?"

Guan: (Nod her head)

Manager: "Since it's you, does the company require you to double-check it before you sign it, and don't make any mistakes, do you?"

Guan had nothing to say.

These examples is to show that facing with higher-ups, people in these two TV series are fear of saying no or express what they are thinking to high social statue.

We all assume that each other is not as busy as ourselves. Others take your efforts for granted, and they must feel more nauseous. If the other party is just deliberately difficult or just want to push things to you, it does not need to compromise. You can say no in a gentle, firm tone, and let the other person walk away. Letting people slaughter is 
tantamount to acquiescing in this kind of thing happening again and again.

\subsubsection{Opposite-gender Friends}

As we mentioned above that the gender difference of rejecting speech act can also be interpreted in the pragmatic framework of speech act theory, face theory, politeness principle and cooperative principle.

Example 1: (2 Broke Girls, Season 2 Episode 12)

Andy: "Hey, is everything okay with your shop? 'Cause the landlord came into my store today and mentioned guys hadn't paid your rent. If there's a problem, I'd be more than happy to help."

Max: "Well, the fact is ,we just don't have."

Caroline: "Don't have a clue why our online payments just never go through. Technology, right? You used to be able to shake them mailman's hand. Now it's all holograms and lasers."

Max: "Granma's right, those were the days. It was a more honset time."

(After Andy's leaving.)

Max: "What's with a lies? Just tell him the truth. We can't pay our rent, life sucks."

\section{Caroline: "No Need."}

Andy: "Hey, Max told me about rent. Why didn't you tell me you guys needed help?"

Caroline: "I guess I just didn't want to have to admit to you or to myself that we're in a real trouble."

Andy: "I want you to have this. Cash it, don't cash it. Do whatever you want, but just know that my success doesn't mean anything if I can't share it with you."

Caroline: "Thank you. Andy, that is so amazing, and I really appreciate it, but I can't take it."

Caroline and Max had no money to pay for rent, Andy knew it. So he asked Caroline whether they need help. Even they really need this money but they still refused.

Example 2: (Ode to Joy, Season 1 Episode 16)

QiDian: "How's it going? Is it so hard to accept my pursuit and admiration?"

Andy: (Keep Silence)

QiDian: "What should I do? I just got here two days before I wanted to go back. I didn't understand until I met you. Human acquaintance is so wonderful that magnetic poles and poles attract each other. It's like a volcano is ISSN: 2456-7620 erupting in my heart. It was both overflowing and quiet. Yes or no? Think carefully about my problem before I come back. I need your answer."

Andy: "My dishes are ready."

When Qi Dian ask Andy for an answer, Andy choose to ignore at first. And then use the excuse "My dishes are ready." to reject him indirect.

From that examples, we can know that both in America or China even the people around the world are hard to refuse the opposite-gender people. Even though they really need help or something. But, the people both in America and China choose to use indirect ways to reject when with opposite-gender friends to saving their face.

\subsection{The Use of Rejection Strategies in Direct Way}

The study found that, in terms of the number, women use more rejection strategies than men; in terms of the type, men use direct verbal strategies and non-verbal strategies such as silence, hesitation, facial expression, and walking away. Women tend to use indirect speech strategies to express their refusal to speak. Although men also have a sense of courtesy and face protection, they are less able to achieve these ends with a variety of pragmatic strategies.

The gender difference of the rejection strategy can be attributed to a variety of reasons, such as the different physiological foundations, social needs and psychological tendencies of the sexes. The two gender lives in different sub-cultural groups tend to follow their fixed communication patterns, such as men tend to use a competitive session model. Women tend to be in the form of a collaborative session. The gender difference of rejecting speech act can also be interpreted in the pragmatic framework of speech act theory, face theory, politeness principle and cooperative principle.

Because the politeness principle under the guidance of social status is more important in customer relationship, this paper chooses the dialogue between friends, which is more extensive in the category of indirect refusal. Indirect denials are further divided into four categories: requests, suggestions, invitations, and offers. These dialogue require a positive response from both sides of the dialogue.

Intimate relationship includes best friend, family or lovers. People often tends to express what they are. So when they ask for help, they will direct to reject it when they are not want to help or be helped. 
For the same scenario, Max and Caroline don't have the money to pay the rent. When Andy wants to help, Caroline reject Andy's help for twice in a indirect way. When it comes to close friend or family, Caroline and Max choose to reject directly and then accept it.

Example 1: (2 Broke Girls, Season 2 Episode 12)

When everyone knows they don't have money to pay for the rent.

Erle: "Caroline called me last night. Told me that you two couldn't pay your rent that you were losing the shop. That girl can talk."

Oleg: "She called me too, and said you didn't have your rent. So we put together what we had, and ...here."

Han: "Consider it an early Christmas gift from all three of us."

Caroline: “Thank you, but we can't take it. Yes, you can. We're family."

Caroline: "500 whole dollars? Thank you, guys."

When come to close friend or family, the same in China.

Example 2:(Ode to Joy, Season 2 Episode 12)

when Andy help Qu Xiaoxiao to deal with the business case, she wants to treat Andy a meal.

Qu Xiaoxiao: “Andy, do you like crabs? I'll bring you some tonight."

Andy: "Don't be so polite. The rest of the work is on your own."

Qu Xiaoxiao: "What are your plans for the evening? I'd like to buy you a casual meal to express my gratitude."

Andy: "Come on. We are neighbors."

Qu Xiaoxiao: “Ok, bye. Neighbors."

We can see in the dialogue, when Qu Xiaoxiao want to buy her a meal, Andy said "Come on, we are neighbors."

When facing the people who really intimate like close friend or family members, they can express their feeling without hesitation. Because they know no matter what happens they can still accept what they really are without pretending. In this kind of relationship, people in the two countries can freely refuse or accept.

\section{THE DIFFERENCES OF REJECTION STRATEGIES IN 2 BROKE GIRLS AND ODE TO JOY}

\subsection{Character Features}

Satire is a common language phenomenon in Chinese ISSN: 2456-7620 communication. It is a kind of speech act and strong language power. Satirical tactics are often used to state facts in a way that allows to talk about it, and uses the common saying that he insinuates the current politics or the speaker. Although 2 Broke Girls lives at the bottom, it does not prevent them from making fun of political and economic scandals, making serious questions to a joke through Max's interpretation.

Example 1: (Season 1 Episode 2)

Caroline:“And I'll do the rest till you believe."

Max:"I believe everything you just said and that chil drenare the future."

When Caroline describes her business ideas, Max uses a soul soup like "believe the child is the sun of tomorrow" to express a negative view, which is the perfect illustration of the beauty strategy. Max has a tenacious spirit. But she could not believe that the world was good for those who did not have high hopes for life. Such a beautiful quote came out of Max's mouth as a sign that she didn't believe Caroline and she could do a good business. The strategy of seeking beauty replaces disbelief with belief and disapproval with consent, which is one of the most ingenious aspects of indirect refusal.

Example 2: (Ode to Joy, Season 1 Episode 13)

Colleague : Xiao Guan, are you busy now? I seem to have caught a cold. I feel terrible.

Guan Zuer: "I have cold medicine here. Here you go."

Colleague: "I have a lot of things in my hand now, and I have to hand them in the morning. There is no time to drink water now."

Guan Zuer: "Well, here's the deal. You do your job first. I'll take it for you."

Colleague: "Thank you. In fact, if I had a good night's sleep, I might be fine tomorrow. But our work is so urgent that we probably have to stay up late again tonight." (pretend coughing)

Guan Zuer: "Well, you send me some of the emails you've finished, and then I'll do mine for you."

Colleague: "Really? That's very kind of you. I'll help you with something next time."

(Then Guan Zuer sent voice messages in a low voice to her friends in WeChat group said: Girls, I'm still not good at rejecting people. It looks like I'm going to work overtime 
again today.)

The Guan Juer in Ode to Joy, for she is sweet-looking and kind-hearted. But she is often criticized, because her heart is too good, she does not know how to refuse others. Guan Ju-er often works late because he works for others. At last, the colleague was ill again and asked her to finish the rest of the work. Finally, she signed and confirmed. Colleagues do that part of the mistakes are missed, the manager only scolded Guan Juer after knowing. Because she was the last person to sign, and she was responsible for all the responsibilities. And the colleague, after the accident did not say a word for her, not a word of comfort. Guan Juer's foolish and sweet behavior is also the portrayal of many people today. Because they want to shape their good image, they refuse to refuse their friends' requests. Finally, we warm others, but tired ourselves.

Example 3: (Season 4 Episode 5)

Caroline: "Do you think other business got successful byleaving early?"

Max:"They did it by hiring legals and moving their $b$ ankaccounts offshore."

Max suggested closing the store early, but Caroline was still willing to stay on the job. She asked Max if she thought other industries were successful by leaving work early. Max respondedquickly and calmly because they hired black workers and moved their bank accounts overseas to evade taxes, as a sign that they would not have succeeded if they did not leave early. From the point of view of indirect refusal, she refused to respond positively to Caroline's question; from the perspective of pragmatic strategy, Max has pointed out some facts to allude to the successful enterprises who walks the sidewalk.

Example 4: (Ode to Joy, Season 1 Episode 1)

( $Q u$ Xiaoxiao had a party with friends to celebrate her recent move. The noise was soloud that the neighbors rested.)

Then, Qiu Yingying knocked her door and said: "Hello, this is 2202 next door. Could you keep your voice down?"

(After a long time, the voice is still loud.)

Fan Shengmei called the residential property to complain. It didn't work.

(And then the cops came.)

Andy said: "I am owners of the 2201, I have checked the noise nuisance standard in Shanghai, China, from 10:30 ISSN: 2456-7620 to 7:00 the next morning more than 55 decibels are disturbing people. If it is late at night more than 15 decibels already constitute a nuisance to the people. It's 12:00, and I've tested your room music with iphone own app decibels over 70 decibels. It reasonable for me to call the police. Of course, if you have any objection, you can also contact my lawyer to sue me at any time. If there is another time, I won't wait for 15 minutes to call the police as it is today. I'll call the police immediately and I'll claim it from you."

Andy, well-dressed, rich in money, first-rate in intelligence, and beautiful in appearance. She spoke bluntly, boldly, decisively and forcefully. Grew up in the United States and not very good at the Chinese more implicit expression. Unlike Guan Juer, Andy is more direct to express her feeling.

Picking good wordis one of the most common strategies for seeking beauty in speech activities. It shows people's pursuit of beauty, their utilitarian purpose and their efforts to remedy unsuitable topics. The strategy of seeking beauty in indirect rejection is to reject others in good language and euphemism. This not only accords with the meaning of indirect refusal, but also accords with the cooperation principle and politeness principle of pragmatics.

A person's value often not built up through affirmation and acceptance, and a proper rejection is more a reflection of one's value. In these two TV series, with the different character the will has different ways to deal with things. Like Max often use humour language to cheer people up and reject it in the same time. Guan is a timid girl, always afraid of whether it is appropriate, then hardly to reject anyone's request even if she do not want to do it at all. Unlike Guan, Andy is confident and power enough, so she won't obey her feelings. When dealing with the same situation, Guan may choose to endure silently, but Andy choose to adopt a harder means --calling the police. From that we can know that the difference in everyone's character makes a difference in the way they refuse.

\subsection{Rejection Modes}

Language is the carrier of culture. Different cultures form different value orientations, which extend to the rejection of speech acts. The Chinese are influenced by collectivism and attach great importance to the harmony between the state, the collective and the individual. 
Therefore, it is more important to think about others first, to think in the position of others, not too direct when expressing rejection, so as not to let others lose face as far as possible. English-speaking countries, because of their outstanding personal value orientation, they pursue freedom and independence. In their view, they use the way to refuse, whether to follow the principle of politeness is a personal matter, it is not much significance to the society. In communication, they prefer to follow their own wishes, so they are more likely to consider themselves first when they reject others.

Chinese often think that refusing someone in face is not so great. So they may say yes at first and then refuse it later on the phone with an excuse.

It can refer that the Guan Juer's brother wants to go home with her. She say yes at first and then refuse it on the phone. (Ode to Joy, Season 1Episode 11)

Unlike Chinese, American is more direct and face-to-face rejection.

Example 1: (2 Broke Girls, Season 1 Episode 3)

Han: "Max, three weeks in a row, you have not yet accept my request to be a Facebook friend." (Max pretended not to hear.)

Han: "Max? I am talking to you."

Max: "I didn't hear you, I have my ear buds in."

(Han picked up the ear buds on the table)

Han: "What are these?"

Max: 'Okay, you had to bust a move, to get "the truth" on my ass? Fine, let's go there. Han, I'm never gonna be your Facebook friends."

Han: "Woo! Hard to hear."

\section{THE CAUSES OF DIFFERENCES IN 2 BROKE GIRLS AND ODE TO JOY}

\subsection{Cultural Background-Hierarchy thought and Equality thought}

The difference between hierarchy thought and equality thought in Chinese and English is also influenced by Chinese traditional hierarchy thought and equality thought in western culture. Hierarchy thought has a long history in China. In ancient times, it changed from matriarchal society to patrilineal society. With the change of social mode of production, the status of men and women in the same tribe changed. In order to maintain the social order and hierarchy, ISSN: 2456-7620 the primitive society formed a feudal patriarchal system composed of political power, clan power, theistic power and husband power according to the relation of kinship and alienation. The feudal society was influenced by Confucianism, and the hierarchical system was gradually developed and perfected. In order to maintain their supreme power status, the rulers established a hierarchical system from top to bottom. There are national laws, family rules, gender differences, differences in generations, subordinates and subordinates, status and prestige have a great impact, to different generations and levels of people, given different names, compared to Western countries, the title is different, compared to the Western countries, the name given to different generations and levels of people, compared to the Western countries, the name given is different, Chinese forms of address can be said to be a variety of, which also reflects the Chinese people treat people with courtesy.

English-speaking Western countries pursue freedom and equality. They have no strict restrictions on the use of address forms, and they can call the names of elders and teachers unscrupulously in public, while in China, This kind of behavior not only reflects a person's lack of accomplishment, but also a kind of offending and harming the face of the other party. Chinese people usually wear a "surname title" when they reject their superiors, while people in English-speaking countries can call their superiors by their first name or replace them with simple "Sir".

\subsection{Particular Environment-Collectivism and Individualism}

The cultural differences between collectivism and individualism in different countries have a great influence on the smooth process of interpersonal communication. Among the many influential conditions, Chinese-English culture embodies the most obvious differences in values. Chinese culture is most influenced by Confucianism. Everyone cannot exist alone from the society, everyone exists in a certain relationship, the whole society is a harmonious system-body, as a member of society, we should look at all things from the overall situation, and be influenced by this kind of thought. You have to think about others, care about others, be humble, and be polite. In the final analysis, it is required that we learn to give up the ego and save the great self in the complicated social relations. 
The vast territory of China, along with the continuous migration and fusion of ancient times, the various nationalities have formed the characteristics of large and small communities, so the Chinese people have a strong collective concept from an early age, and in the long social life, people have formed mutual help and mutual assistance. A collective consciousness that depends on one another. In addition to the thousands of years of natural economic development, the Chinese people who grew up in this situation regard themselves as a member of the collective, and the value of the individual can only be realized in the collective. Collectivism is the core of Chinese social values, and it plays a guiding role in people's values and values pursuit.

The majority of English-speaking countries take western ideology as the mainstream. Most of them belong to capitalist countries. The Renaissance movement based on ancient Greek culture and Roman culture in the 14th to 16th centuries is a ideological liberation movement that promotes the progress of human society. It also promoted the formation of the value concept of western individualism. Puritans had a profound influence on the development of Western culture. They advocated industriousness and economy and believed that they could change society on their own. Take the United States as an example, influenced by bourgeois liberties, equality, and fraternity, the pursuit of personal values and material wealth is the dream of many people, and many people of humble origin expect to rely on their constant efforts to achieve their ideals and aspirations. All these unknowingly promoted the development of individualistic values.

\section{CONCLUSION}

Some people dare not refuse others' requests because they feel that once they refuse, they do not attach importance to each others friendship, or worry about creating an embarrassing atmosphere. The "great good man" should take some time to listen to each others difficulties and even encourage him to feel your concern for him. Sometimes, the person ask for help is just looking for someone to talk to and soothe his anxiety and share the pressure. He doesn't have to ask for your help. If you refuse the invitation, you can thank the other party for your kind invitation, or then take the initiative to care about the ISSN: 2456-7620 participants. Awkward situations can sometimes be avoided, if the other side is angry, but also calmly express your regret for his reaction, and still wish him a smooth solution to the problem.

Through the study of pragmatic principles and strategies of indirect refusal in 2 Broke Girls and Ode to Joy, this paper provides an approachable language learning style for English learners in non-English-speaking countries. The answer can be found in the American TV series, which provides a wealth of cases for pragmatic studies and cross-cultural communication studies.

Due to the characteristics of English and Chinese language, speech act theory provides a basic starting point for this thesis. Politeness theory and relevance theory are the theoretical basis and tools for the study of rejection strategies. This paper attempts to explain the application of relevance theory to language relevance in rejection situations. From the perspective of relevance theory, "rejection" can be understood as a choice with dynamic contextual assumptions made by the communicative party in the process of conversational interaction in response to the requests, invitations, suggestions, and offers made by the other party. The process of using refusal can be regarded as the best relevance choice for a set of contextual assumptions in order to satisfy the communicative purpose of the communicator and obtain the success of communication. The different choices made by different groups form the diversity of rejection strategies. The impact of social status and gender differences on relevance, which is precisely the content of politeness theory. So far, the two theories are well integrated to explain the similarities and differences of rejection strategies between China and the United States.

\section{REFERENCES}

[1] Austin, J.L. How to Do Things with words [M].Oxford: Clarendon press.(1962)

[2] Bi Jiwang. Research on the Cultural Characteristics of Politeness[J].Chinese Teaching In The World.1996(01): 53-59.

[3] Brown, P. \& S. Levinson. Politeness: Some Universals in Language Usage $[\mathrm{M}]$. Cambridge: Cambridge University Press, 1987. 
[4] Cheng Guipin. Comparison of Chinese and English Refusals and their application in cross-cultural communication[D]. Henan University 2015.

[5] Chen Liufang, Qu Weiguo. View On the Traditional Chinese Politeness Principle[J]. Academic Monthly. 1999(07): 33-41.

[6] Gudykunst \& William B. Theorizing About Intercultural C ommunication $[\mathrm{M}]$. Thousands California: Sage Publications, Inc., 2005.

[7] Lakoff\& Robin T. Talking Power: The Politics of Languag $e$ in Our Lives [M]. NewYork: Basic Books, 1990.

[8] Leech, G. Principles of Pragmatics [M]. New York: Long man Group Ltd., 1983.

[9] Li Wei, Wang Shao. An Empirical Study on the Pragmatic Transfer of Refusal Speech Act[J].Foreign Language Research. 2007(04) : 77-81.

[10] Ma Yuelan. A Comparative Study on the Commonness of Chinese and American Rejection Strategies[J]. Journal of Xi'an International Studies University. 2000 (02) : 46-49.

[11] Pan Min. A Comparative Study of Refusal Strategies in English and Chinese Speech Acts[J]. Heihe Journal. 2005 (050) : 66-69

[12] Tang Lin. Analysis of the Surface Strategies of Chinese Indirect Refusal of Speech Act[J]. Guangxi Social Sciences.2004(10): 117-119.

[13] Wang Aihua. A Survey of Expression Patterns of Rejection in English and Chinese[J]. Foreign Language Teaching and Research.2001(03): 178-185.

[14] Wu Jianshe. The Expression of a refusal [J]. Journal of Sichuan International Studies University. 2003(04): 106-109.

[15] Yi Hongchuan. The Politeness Principle of Chinese and Communicative Culture[J].Language Planning. 1991(08):11-15. 